\title{
Allergic Rhinitis in Relation to Food Allergies Pointers to future research
}

Rashid Al-Abri, ${ }^{1}$ Asdaf S. Al-Amri, ${ }^{2}$ Zaina Al-Dhahli, ${ }^{3}$ "Ajoy M. Varghese ${ }^{1,4}$

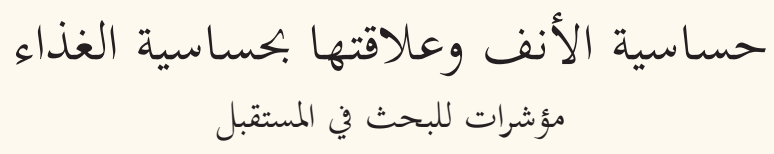

راشد العبري، أصداف صالح العامري، زينة الذهلي، اجوي ماثيو فارغيس

ABSTRACT: Allergic rhinitis is a ubiquitous type of allergic reaction which results in significant costs to affected patients and their families. Although allergic rhinitis can coexist with other atopic conditions, the role of food allergies in the development of allergic rhinitis has not been well studied. This article explores relevant literature on this subject in order to identify gaps in the available body of knowledge and elucidate scope for further research.

Keywords: Allergic Reactions; Respiratory Hypersensitivity; Allergic Rhinitis; Food Allergies; Allergens.

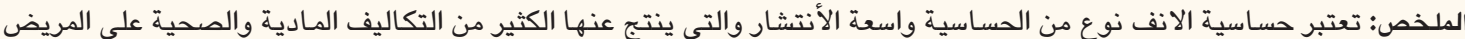

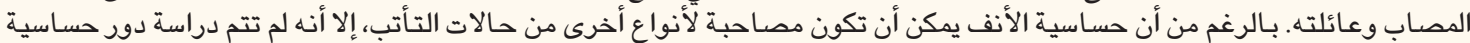

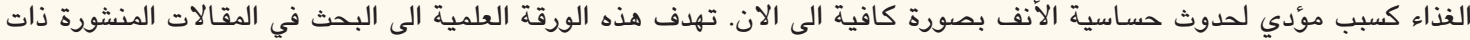

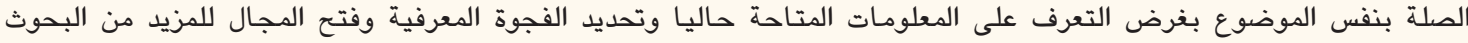

$$
\begin{aligned}
& \text { والدراسات المستقبلية. } \\
& \text { الكلمات المفتاحية؛ التفاعل التحسسي؛ فرط الحساسية الرئوي؛ الحساسية الأنفية؛ حساسية الغذاء؛ المواد المثيرة للحساسية. }
\end{aligned}
$$

A LLERGIC RHINITIS IS ONE OF THE MOST common diseases worldwide and usually persists throughout the lifetime of the affected patient. Although allergic rhinitis is not associated with significant morbidity or mortality, the burden and cost of this disease are substantial. ${ }^{1}$ This condition is not only associated with impaired quality of sleep and cognitive function but is also a significant contributor to reduced work performance and increased school absenteeism, with resulting indirect costs greater than those incurred by asthma. ${ }^{2}$ Although allergic rhinitis is an organ-specific disorder, it frequently coexists with other allergic manifestations like asthma and eczema. The presence of rhinitis is a significant risk factor for asthma and the coexistence of rhinitis is associated with poor asthma control. ${ }^{3}$ Similarly, allergic rhinitis is the most common concomitant allergic disease associated with eczema. ${ }^{4}$

One suggested mechanism to explain the connection between common atopic disorders such as eczema, asthma and allergic rhinitis is atopic march, which proposes that the allergic disease progresses from atopic dermatitis to asthma and, subsequently, to allergic rhinitis. ${ }^{5}$ Pols et al. observed that the prevalence of the coexistence of all three atopic diseases was 9.8 times higher than that which would be expected by chance; moreover, the relative risk for the occurrence of asthma and eczema in patients with allergic rhinitis was 6.20 (95\% confidence interval: 5.30-7.27). ${ }^{6}$ Similarly, the link between food allergies, asthma and eczema has been well-studied. ${ }^{7,8}$ However, the same cannot be said of the relationship between food allergies and allergic rhinitis. This article explores the available body of knowledge on food allergies and allergic rhinitis in order to elucidate potential pointers for future research.

\section{Pathogenesis of Food Allergies}

Adverse food reactions encompass all abnormal clinical responses to the ingestion of food and can result from either an intolerance or allergy [Figure 1]. ${ }^{9}$ The former refers to an adverse reaction to an inherent property of the food item (i.e. toxic contamination) and is beyond the scope of this article. In contrast, a food allergy is an abnormal immunological response which may or may not be mediated by immunoglobulin E (IgE). ${ }^{9}$ When the gastrointestinal barrier breaks down-either due to increased permeability, as in infants, or due to an inflammatory process - sensitisation to the allergenic antigens occurs. Occasionally, sensitisation can occur via the respiratory tract or skin, bypassing the gastrointestinal 


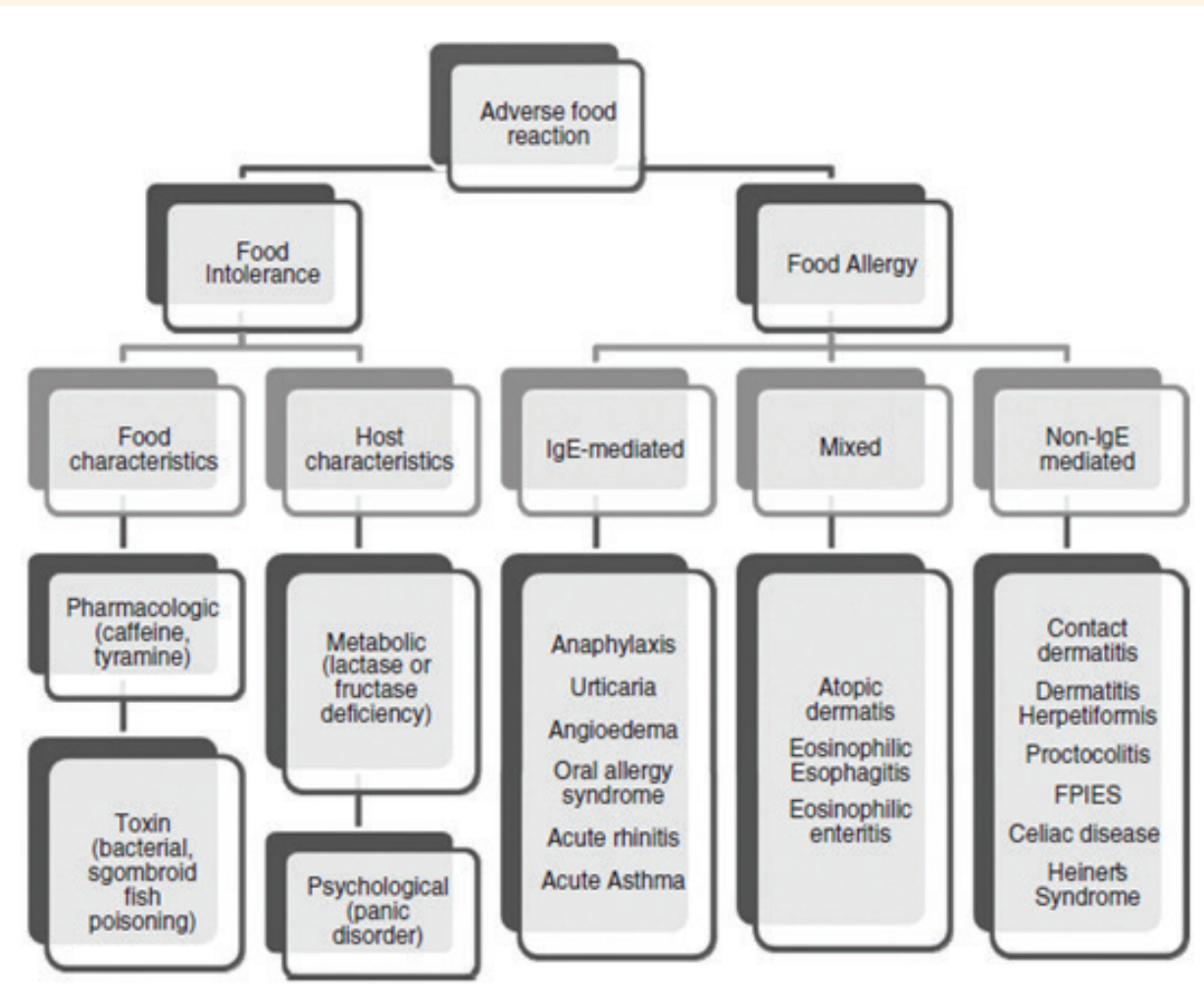

Figure 1: Classification of various food-related adverse reactions. $I g E=$ immunoglobulin E; FPIES = food protein-induced enterocolitis syndrome. Reproduced with permission from Cianferoni A, Spergel JM. Food allergy: Review, classification and diagnosis. ${ }^{9}$

barrier, as with oral allergy syndrome or pollen allergy syndrome. ${ }^{9}$ Food sensitisation is considered an important risk factor for developing respiratory allergies.

In the classic IgE-mediated pathway, which occurs among individuals who have been exposed to the allergen and have had an initial immune response, subsequent exposure to the allergen triggers IgE-mediated degranulation of mast cells and basophils, resulting in allergic symptoms. ${ }^{10-12}$ On the other hand, non-IgEmediated food allergies, such as food protein-induced enterocolitis syndrome, food protein-induced proctocolitis and food protein enteropathy, are less common and are usually due to a chronic inflammation of the gastrointestinal tract; such conditions are mediated through allergen-specific $\mathrm{T}$ cells or eosinophils and primarily affect the gastrointestinal rather than respiratory tract. ${ }^{13}$

Allergic rhinitis is more frequently associated with a secondary rather than a primary food allergy. A secondary food allergy, also known as pollen food syndrome, involves cross-reactivity in patients with pollen allergies who develop allergic symptoms to certain types of food; it is a mild food allergy and has been associated with polyvalent airborne allergens. ${ }^{4,14}$ Although no specific genes have been identified, food allergies are at least in part genetically determined, with various studies confirming patterns of familial inheritance. ${ }^{15,16}$ Polymorphisms in up to nine genes have been associated with the incidence or severity of food allergies, including the CD14, forkhead box P3, signal transducer and activator of transcription 6, serine protease inhibitor kazal type 5 and interleukin 10 genes. ${ }^{17}$ However, most of these findings need to be replicated in other populations. Links between food allergies and several human leukocyte antigen (HLA) genotypes have also been found, with significant associations reported between $H L A$ class II DR $\beta-1$ (HLA-DRB1), DQ $\beta-1$ and $D P \beta-1$ gene polymorphisms and peanut allergies as well as between the HLA-DRB1*07 allele and apple allergies. ${ }^{17}$ The recent increase in the prevalence of allergic disease has been attributed to either an increase in exposure to allergens among genetically predisposed individuals or via a heritable epigenetic mechanism from events that occurred while the baby was in utero. ${ }^{18}$ This is an exciting area for further research.

The coexistence of various allergic symptoms in the same individual cannot be explained by chance. One concept that explains this is the previously described allergic march hypothesis, which suggests a progression of symptoms from eczema and food allergies to asthma and allergic rhinitis; the later presentation of allergic rhinitis in relation to food allergies supports this concept. ${ }^{2}$ Using Bayesian machine learning methods 
on two large cohorts, Belgrave et al. suggested that this is only one of several mechanisms and concluded that heterogeneous patterns exist, with different manifestations sometimes existing independently. ${ }^{19}$ A few studies have suggested that patients with food allergies have an increased risk of developing respiratory allergies; however, these studies were relatively small and relied primarily on self-reported data. ${ }^{7,20}$ Of the major food allergens, peanut, milk and egg allergies significantly predispose individuals to the development of both allergic rhinitis and asthma. Additionally, patients with multiple food allergies are at increased risk of developing allergic rhinitis and asthma as compared to patients with a single food allergy. ${ }^{21}$ Further research on the causal relationship between food allergies and allergic rhinitis may shed more light on this topic.

\section{Allergic Rhinitis and Food Allergies in Children}

Children may be affected by different or co-existing allergic and atopic manifestations. Although allergic rhinitis affects about a third of the population, the greatest frequency of the condition is found in children and adolescents. ${ }^{22}$ The coexistence of primary food allergies and allergic rhinitis in children has been studied in a few cohort studies. In a prospective longitudinal birth cohort study in Sweden, Goksör et al. concluded that $40 \%$ of children with food allergies in infancy had allergic rhinitis by the time they were eight years old. ${ }^{23}$ The onset of the food allergy was found to precede the onset of allergic rhinitis, with $47 \%$ of the children initially developing the food allergies within one year of birth while only $7.9 \%$ of children with allergic rhinitis developed the condition before two years of age; the mean age of onset of the food allergies was one year and two months, which was much earlier than the mean age at diagnosis of the allergic rhinitis at four years and nine months. ${ }^{23}$ Although an early food allergy appears to be the strongest predictor of subsequent allergic disease, allergic march is only one of several postulated causal mechanisms.

The increased prevalence of allergic rhinitis in older children may be explained by their increased sensitisation to airborne allergens once they reach school age. In a retrospective cohort study of paediatric patients with established food allergies, Hill et al. found that 35\% went on to develop allergic rhinitis. ${ }^{21}$ Additionally, the food allergens most likely to cause allergic rhinitis were peanuts, milk and eggs (odds ratios: 2.59, 1.46 and 1.8, respectively). ${ }^{22}$ In a study of French schoolchildren, Pénard-Morand et al. concluded that self-reported food allergies, food sensitisation and skin prick-tested food allergies were all significantly positively associated with allergic rhinitis; moreover, these associations persisted even when the food allergy did not result in any respiratory symptoms $(P<0.001){ }^{24}$

\section{Allergic Rhinitis and Food Allergies in Adults}

True food allergies occur at a rate of $0.1-1 \%$ in adults. ${ }^{25,26} \mathrm{Al}$-Rabia suggested that the peak prevalence was between 21-40 years of age, after which it decreased. ${ }^{27}$ However, the available literature regarding adult allergies is limited in comparison to that of paediatric allergies. Among adults, the prevalence of food allergies varies according to culture and population. In a retrospective analysis of in vitro enzyme-linked immunosorbent assay results, Sahin-Yilmaz et al. found that the most common food allergens associated with allergic rhinitis among adults in the USA were peanuts (23.4\%) and shrimp (22.2\%), whereas allergies to milk (13.2\%) were much less frequent. ${ }^{28}$ This seems to indicate that while children tend to outgrow most common food allergies, others like peanut and crustacean allergies persist into adulthood. Among the allergens tested, peanuts had a $100 \%$ specificity and $100 \%$ positive predictive value in diagnosing food allergies with low sensitivity (26.7\%) and a negative predictive value (48.8\%). ${ }^{28}$

Kumar et al. identified positive skin prick tests to one or more foods among 29.3\% of Indian adult and adolescents with asthma and allergic rhinitis. ${ }^{29}$ In contrast, rice (6.2\%) and black gram legumes (5.9\%) were the most common allergens, while peanuts and soybean allergens were less frequent (2-3\%). ${ }^{29}$ Moreover, citrus fruits and chocolate have been reported to be the primary food allergens in the Mediterranean region and Russia, while nuts, apples, pears and kiwifruit allergens are most common in Denmark and Sweden..$^{30}$ Additional research is therefore needed to identify the prevalence of specific allergens in other populations.

\section{Conclusion}

The development of allergic disease is complex and not well understood. Various manifestations can coexist based on individual susceptibility and exposure to different environmental factors. Early food allergies appear to be the strongest predictor of subsequent allergic disease. In terms of natural history, allergic march is a credible theory, particularly as allergic rhinitis usually presents later than food allergies. However, additional studies are needed to understand the relation between food allergies and allergic rhinitis. Exciting areas for future research include the role of genetics and epi- 
genetics, the identification of specific food allergens that cause allergic rhinitis and the prevalence of various allergens in different regions of the world.

\section{References}

1. Zuberbier T, Lötvall J, Simoens S, Subramanian SV, Church MK Economic burden of inadequate management of allergic diseases in the European Union: A GA(2) LEN review. Allergy 2014; 69:1275-9. doi: 10.1111/all.12470.

2. Camelo-Nunes IC, Solé D. Allergic rhinitis: Indicators of quality of life. J Bras Pneumol 2010; 36:124-33. doi: 10.1590/ S1806-37132010000100017.

3. de Groot EP, Nijkamp A, Duiverman EJ, Brand PL. Allergic rhinitis is associated with poor asthma control in children with asthma. Thorax 2012; 67:582-7. doi: 10.1136/thoraxjnl2011-201168.

4. Cingi C, Gevaert P, Mösges R, Rondon C, Hox V, Rudenko M, et al. Multi-morbidities of allergic rhinitis in adults: European Academy of Allergy and Clinical Immunology Task Force Report. Clin Transl Allergy 2017; 7:17. doi: 10.1186/s13601-0170153-z.

5. Sun HL, Yeh CJ, Ku MS, Lue KH. Coexistence of allergic diseases: Patterns and frequencies. Allergy Asthma Proc 2012; 33:e1-4. doi: 10.2500/aap.2012.33.3506.

6. Pols DH, Wartna JB, van Alphen EI, Moed H, Rasenberg N, Bindels PJ, et al. Interrelationships between atopic disorders in children: A meta-analysis based on ISAAC questionnaires. PLoS One 2015; 10:e0131869. doi: 10.1371/journal.pone.0131869.

7. Liu AH, Jaramillo R, Sicherer SH, Wood RA, Bock SA, Burks AW, et al. National prevalence and risk factors for food allergy and relationship to asthma: Results from the National Health and Nutrition Examination Survey 2005-2006. J Allergy Clin Immunol 2010; 126:798-806.e13. doi: 10.1016/j.jaci.2010.07.026.

8. Saunes M, Øien T, Dotterud C, Romundstad PR, Storrø O, Holmen TL, et al. Early eczema and the risk of childhood asthma: A prospective, population-based study. BMC Pediatr 2012; 12:168. doi: 10.1186/1471-2431-12-168.

9. Cianferoni A, Spergel JM. Food allergy: Review, classification and diagnosis. Allergol Int 2009; 58:457-66. doi: 10.2332/aller golint.09-RAI-0138.

10. Yu W, Freeland DM, Nadeau KC. Food allergy: Immune mechanisms, diagnosis and immunotherapy. Nat Rev Immunol 2016; 16:751-65. doi: 10.1038/nri.2016.111

11. Sicherer SH, Sampson HA. Food allergy: Recent advances in pathophysiology and treatment. Annu Rev Med 2009; 60:261-77. doi: 10.1146/annurev.med.60.042407.205711.

12. Lee LA, Burks AW. Food allergies: Prevalence, molecular characterization, and treatment/prevention strategies. Annu Rev Nutr 2006; 26:539-65. doi: 10.1146/annurev.nutr.26.061505.111211.

13. Nowak-Wegrzyn A, Katz Y, Mehr SS, Koletzko S. Non-IgEmediated gastrointestinal food allergy. J Allergy Clin Immunol 2015; 135:1114-24. doi: 10.1016/j.jaci.2015.03.025

14. Czarnecka-Operacz M, Jenerowicz D, Silny W. Oral allergy syndrome in patients with airborne pollen allergy treated with specific immunotherapy. Acta Dermatovenerol Croat 2008; 16:19-24.

15. Tsai HJ, Kumar R, Pongracic J, Liu X, Story R, Yu Y, et al. Familial aggregation of food allergy and sensitization to food allergens: A family-based study. Clin Exp Allergy 2009; 39:101-9. doi: 10.1111/j.1365-2222.2008.03111.x.
16. Hourihane JO, Dean TP, Warner JO. Peanut allergy in relation to heredity, maternal diet, and other atopic diseases: Results of a questionnaire survey, skin prick testing, and food challenges. BMJ 1996; 313:518-21. doi: 10.1136/bmj.313.7056.518.

17. Hong X, Tsai HJ, Wang X. Genetics of food allergy. Curr Opin Pediatr 2009; 21:770-6. doi: 10.1097/MOP.0b013e32833252dc.

18. National Academies of Sciences, Engineering, and Medicine. Potential genetic and environmental determinants of food allergy risk and possible prevention strategies. In: Finding a Path to Safety in Food Allergy: Assessment of global burden, causes, prevention, management, and public policy. Washington D.C., USA: National Academies of Sciences, Engineering, and Medicine, 2017. Pp. 139-226.

19. Belgrave DC, Granell R, Simpson A, Guiver J, Bishop C, Buchan I, et al. Developmental profiles of eczema, wheeze, and rhinitis: Two population-based birth cohort studies. PLoS Med 2014; 11:e1001748. doi: 10.1371/journal.pmed.1001748.

20. Friedlander JL, Sheehan WJ, Baxi SN, Kopel LS, Gaffin JM, Ozonoff A, et al. Food allergy and increased asthma morbidity in a school-based inner-city asthma study. J Allergy Clin Immunol Pract 2013; 1:479-84. doi: 10.1016/j.jaip.2013.06.007.

21. Hill DA, Grundmeier RW, Ram G, Spergel JM. The epidemiologic characteristics of healthcare provider-diagnosed eczema, asthma, allergic rhinitis, and food allergy in children: A retrospective cohort study. BMC Pediatr 2016; 16:133. doi: 10.1186/s12887-016-0673-z.

22. Sih T, Mion O. Allergic rhinitis in the child and associated comorbidities. Pediatr Allergy Immunol 2010: 21:e107-13. doi: 10.1111/j.1399-3038.2009.00933.x.

23. Goksör E, Loid P, Alm B, Åberg N, Wennergren G. The allergic march comprises the coexistence of related patterns of allergic disease not just the progressive development of one disease. Acta Pediatrica 2016; 105:1472-9. doi: 10.1111/apa.13515.

24. Pénard-Morand C, Raherison C, Kopferschmitt C, Caillaud D, Lavaud F, Charpin D, et al. Prevalence of food allergy and its relationship to asthma and allergic rhinitis in school children. Allergy 2005; 60:1165-71. doi: 10.1111/j.1398-9995.2005. 00860.x.

25. Boye JI. Food allergies in developing and emerging economies: Need for comprehensive data on prevalence rates. Clin Trans Allergy 2012, 2:25. doi: 10.1186/2045-7022-2-25.

26. Turnbull JL, Adams HN, Gorard DA. Review article: The diagnosis and management of food allergy and food intolerances. Aliment Pharmacol Ther 2015; 41:3-25. doi: 10.1111/ apt.12984.

27. Al-Rabia MW. Food-induced immunoglobulin E-mediated allergic rhinitis. J Microsc Ultrastruct 2016; 4:69-75. doi: 10.10 16/j.jmau.2015.11.004.

28. Sahin-Yilmaz A, Nocon CC, Corey JP. Immunoglobulin E-mediated food allergies among adults with allergic rhinitis. Otolaryngol Head Neck Surg 2010; 143:379-85. doi: 10.1016/j. otohns.2010.04.271.

29. Kumar R, Kumari D, Srivastava P, Khare V, Fakhr H, Arora N, et al. Identification of IgE-mediated food allergy and allergens in older children and adults with asthma and allergic rhinitis. Indian J Chest Dis Allied Sci 2010; 52:217-24.

30. Eriksson NE, Möller C, Werner S, Magnusson J, Bengtsson U, Zolubas M. Self-reported food hypersensitivity in Sweden, Denmark, Estonia, Lithuania, and Russia. J Investig Allergol Clin Immunol 2004; 14:70-9. 